\title{
MORPHOLOGICAL FEATURES ON MYOCARDIAL BRIDGES AT THE ANTERIOR INTERVENTRICULAR ARTERY
}

\section{Nitu Radu1, Bordei Petru', Baz Radu', Ispas Viorel'}

${ }^{1}$ Faculty of Medicine, University "Ovidius" of Constanta, Romania

Faculty of Medicine, Univeristy „, Ovidius” of Constanta, Universitatii Alee No. 1, Campus B, Constanta, Romania email:vyos@yahoo.com phone: +40723646371

\begin{abstract}
Are described morphological features of myocardial bridges at the anterior interventricular artery obtained from the analysis of 274 cases with 312 myocardial bridges detected by angioCT performed over a period of 3.5 years on a total of 2857 subjects. CT examinations were performed on 1496 females, aged 56-79 years, and 1361 male subjects aged 34-74 years. At the level of the anterior interventricular artery we encountered 231 cases with myocardial bridges (84.31\% of the total number of cases), being 267 myocardial bridges $(85.58 \%$ of the total bridges analyzed). In the case of single myocardial bridges of the anterior interventricular artery, in 65 cases (33.33\% of the 195 cases) they were located in the upper third of the artery, 32 cases were female (31.68\% of female myocardial bridges) and 33 in male sex (35.11\% of male myocardial bridges). In 129 cases (66.67\%) were located in the middle third of the artery, 69 cases were female (63.30\% female myocardial bridges) and 60 cases in male (64.89\% of male myocardial bridges). In one case with three myocardial bridges, the inferior myocardial bridge was located in the lower third of the anterior interventricular artery. The length of the myocardial bridge was between 11.9 and $73.1 \mathrm{~mm}$, for the female gender being 11.9-28.7 mm, and male 9.4-73.1 $\mathrm{mm}$. The thickness of the myocardial bridge was found between 0.9-5.7 mm, for the female gender being 0.9-5.2 $\mathrm{mm}$, and for the male the thickness was 1.7-5.7 mm. The caliber of the tunneling artery was found between 1.2-2.5 mm in female gender, for the male gender 1.3-4 $\mathrm{mm}$.
\end{abstract}

Keywords: anterior interventricular artery - myocardial bridges - morphology

\section{Introduction.}

The myocardial bridge is a congenital abnormality in which a coronary artery branch has an intramiocardial tract in a certain segment thereof, at a variable depth in the subepicardial myocardium which, after $(1,2)$, was due to a defect in the resorption of subepicardial periarterial muscles, as a result of an evolutionary remnant in the genetic code. $(3,4,5,6)$ consider it a congenital anomaly, being a common, normal $(6,7,8,9)$ anatomical variant that is benign $(10,11)$. The myocardial tissue that covers the artery is called a myocardial bridge, and the artery covered by myocardial tissue is called a tunneling artery or tunneling segment.
The myocardial bridge was described in 1737 by autopsy by Reyman and Iwin $(1,4,6,12$ 17) and then by Black in $1805(14,15)$ a deep analysis of its features being made by Geiringer in $1951(1,13-15,18)$. After $(18,19,20)$, the first documentation on myocardial bridges would be made in 1920 by the romanian Crăiniceanu. In 1960, Portsman and Iwig made their first radiological description $(1,4,6,12,13,14,16,17)$. The frequency of myocardial bridges discovered by angiography varies between $0.87 \%$ (17) and $58 \%(21)$, and is less than the frequency of cases discovered by autopsy or dissection, ranging from $41 \%$ (12) to $8 \%$ (Stables). The myocardial bridge most common concerns an arterial segment (14), and rarely a collateral or terminal branch 
of a coronary artery (2). Also, the frequency of location of myocardial bridges differs greatly, most of the authors considering that the presence of the myocardial bridge in the left coronary artery, and the most frequent occurrence is at the level of the anterior interventricular artery, the statistics being very variable ranging from $35.37 \%$ (22) to $94.97 \%$ (9) or even $96.52 \%$ (23). Myocardial bridges are classified as complete or incomplete, being single or multiple (two, three in the same artery or different coronary branches). Depending on the thickness of the myocardium covering the myocardial bridge, it may be superficial, more frequently, having a thickness of $0.3-2 \mathrm{~mm}$, or deep, having a thickness greater than $2 \mathrm{~mm}$. The length of myocardial bifurcation may be between $4 \mathrm{~mm}$ (16) and $45 \mathrm{~mm}$ (15), often between 40-42.8 mm (12, 16, 22, 23, 24). The clinical significance of myocardial bridges is still questionable, with debates on asymptomatic myocardial bridges and symptomatic myocardial bridges (most of the authors) may be a contributing factor to cardiac complications (systolic compression, myocardial ischaemia, angina pectoris, circulatory disturbances, conductive disturbances, myocardial infarction, sudden death), disorders that requires a medical treatment or surgery. There are authors who state that myocardial bridges provide a "protective effect" for atherosclerosis within the coronary artery $(12,19,20,21,26,27)$.

\section{Materials and methods}

Our results on the morphological characteristics of myocardial bridges were obtained from the CT coronarography analysis, the patients being from the Dobrogea area, the coronarographies being performed on a GE LightSpeed VCT64 Slice CT. The CT examinations were performed on a total of 2857 people, of which 1496 were female $(52.36 \%$ of cases), aged between 56-79 years and 1361 male $(47.64 \%$ of cases) aged $34-74$ years. The study was conducted over 3.5 years (2011-2014), with 452 persons, 238 female and 214 male subjects being examined in 2011; in 2012 were examined 694 persons, 363 female and 331 male; in 2013, 1050 people, 549 female and 501 male, were examined; in the first six months of 2014,
661 people, 346 female and 315 male subjects were examined. The following were observed: location, length and thickness of the myocardial bridge, diameter and surface of the tunneling vessel, the patients sex and age.

\section{Results}

At the level of the anterior interventricular artery, 231 cases with myocardial bridges (84.31\% of the total cases and $93.15 \%$ of the left coronary artery) occurred, with 267 myocardial bridges $(85.58 \%$ of the total bridges analyzed and $94.01 \%$ of the left coronary artery bridges), 195 bridges being unique $(62.5 \%$ of the total bridges, $68.66 \%$ of the left coronary artery bridge and $73.03 \%$ of the anterior interventricular artery bridges) in 36 cases there were double bridges (13.14\% of all cases, $14.52 \%$ of left coronary arteries and $15.58 \%$ of anterior interventricular arteries), thus 72 myocardial bridges $(23.08 \%$ of total bridges, $25,35 \%$ of the left coronary artery bridge and $26.97 \%$ of the anterior interventricular artery bridge).

In female interventricular artery, we have met 122 cases with myocardial bridge $(44.23 \%$ of all cases, $49.19 \%$ left coronary artery, $52.81 \%$ of anterior interventricular artery cases and $85.40 \%$ of cases females), finding 143 myocardial bridges $(45.83 \%$ of total bridges, $50.32 \%$ of the left coronary artery bridges, $53.56 \%$ of anterior interventricular artery and $94.70 \%$ of female myocardial bridges). Single myocardial bridges were 101 cases (32.37 of all myocardial bridges, $35.56 \%$ of left coronary artery bridges, $37.83 \%$ of anterior interventricular artery bridges, and $66.89 \%$ of female myocardial bridges). In 21 cases $(7.66 \%$ of all cases, $8.47 \%$ of cases of left coronary artery, $9.09 \%$ of cases of anterior interventricular artery and $17.21 \%$ of female cases) myocardial bridges were doubled, being 42 myocardial bridges $(23.08 \%$ of total bridges, $25.35 \%$ of left coronary artery bridges, $53.56 \%$ of anterior interventricular artery and $27.81 \%$ of female bridges).

For men, at the level of the anterior interventricular artery, we encountered 109 cases with myocardial bridges $(39.78 \%$ of all cases, $43.95 \%$ of cases of left coronary artery, $47.19 \%$ of cases of anterior interventricular artery and 
$83.21 \%$ of the male cases), and there are 124 myocardial bridges $(39.74 \%$ of the total bridges, $43.66 \%$ of the left coronary artery bridges, $46.44 \%$ of the anterior interventricular artery bridges and $94.66 \%$ of the male myocardial bridges). Single myocardial bridges were in 94 cases $(3.13 \%$ of total bridges, $33.1 \%$ of the left coronary artery bridge, $32.21 \%$ of the anterior interventricular artery bridges, and $86.24 \%$ of the male myocardial bridges). In 14 cases (5.11\% of all cases, $5.65 \%$ of left coronary artery cases, $6.24 \%$ of previous interventricular artery cases and $11.29 \%$ of male cases) were doubled, there were 28 myocardial bridges $(8.97 \%$ of total bridges, $9.82 \%$ of the left coronary artery bridges, $10.49 \%$ of the anterior interventricular artery bridge, and $22.58 \%$ of the male bridges).

We encountered only one case $(0.36 \%$ of all cases, $0.40 \%$ of the left coronary artery cases, $0.43 \%$ of the anterior interventricular artery cases and $0.92 \%$ of male cases) with 3 myocardial bridges in the anterior interventricular artery $(0.96 \%$ of total bridges, $1.05 \%$ of left coronary artery bridges, $1.30 \%$ of anterior interventricular artery bridges and $2.03 \%$ of male bridges) in a male subject, 70 years-old, the bridges location in the cranio-caudal direction being the following: superior, $0.9 \mathrm{~mm}$ thick in the upper middle third of the artery, $43.1 \mathrm{~mm}$ long and $1.7 \mathrm{~mm}$ tunneling diameter ; middle, $2.1 \mathrm{~mm}$ thick, located in the middle $1 / 3$ of the anterior interventricular artery, a length of $11.9 \mathrm{~mm}$ and a tunneling diameter of $1.8 \mathrm{~mm}$; inferior, $1.6 \mathrm{~mm}$ thick, located in the lower third of the artery, $16.7 \mathrm{~mm}$ long and 1.8 mm tunneling diameter; is the only case where we have encountered a myocardial bridge at the lower third of the anterior interventricular artery.

In the case of single myocardial bridges of the anterior interventricular artery, in 65 cases (33.33\% of the 195 cases) they were located in the upper third of the artery, 32 cases were female (31.68\% of female bridges) and 33 in male (35.11\% of male bridges). In 130 cases $(66.67 \%)$ were located in the middle third of the artery, 69 cases were female $(63.30 \%$ female bridges) and 61 cases male ( $64.89 \%$ of male bridges).

In both genders, we have not encountered any case where the myocardial bridge (single or double) to be located in the terminal segment of the anterior interventricular artery. For double bridges in the anterior interventricular artery, one of them was located in the upper third of the artery and the other in the middle third of the artery.

The length of the myocardial bridge was between 11.9 and $73.1 \mathrm{~mm}$, the female gender being 11.9-28.7 $\mathrm{mm}$, and the male gender 14$73.1 \mathrm{~mm}$. Thickness of the myocardial bridge was 0.9-5.7 $\mathrm{mm}$, with female gender 0.9-5.7 $\mathrm{mm}$, and male 1.7-5.7 $\mathrm{mm}$. The myocardial bridge area was between 1.3-4.5 mm2 in females, and in the male gender between 1.2-5.6 $\mathrm{mm} 2$. The caliber of the tunneling artery was found to be between $1.2-2.2 \mathrm{~mm}$ in females, and in male to $1.3-4 \mathrm{~mm}$.

\section{Discution}

Table 1 The location frequency of the anterior interventricular artery myocardial bridges

\begin{tabular}{|l|c|c|}
\hline Author & $\begin{array}{c}\text { Myocardial } \\
\text { bridges } \\
\text { number }\end{array}$ & $\begin{array}{c}\text { Anterior } \\
\text { interventricular } \\
\text { artery bridges }\end{array}$ \\
\hline Irvin & 35 & $35-(100 \%)$ \\
\hline Gow & 200 & $69-(34,5 \%)$ \\
\hline Konen & 47 & $34-(72,34 \%)$ \\
\hline Kantarci & 22 & $22-(100 \%)$ \\
\hline Loukas & 69 & $35-(50,72 \%)$ \\
\hline Zeina & 78 & $48-(61,54 \%)$ \\
\hline Carrascosa & 159 & $104-(65,41 \%)$ \\
\hline Liu H & 174 & $167-(95,98 \%)$ \\
\hline Jin Ho Hwang & 557 & $550-(98,74 \%)$ \\
\hline Jodocy & 50 & $34-(68 \%)$ \\
\hline En-Sen Ma & 389 & $235-(60,41 \%)$ \\
\hline Yu-Jun Niu & 140 & $120-(85,71 \%)$ \\
\hline Sildiroglu & 93 & $81-(87,1 \%)$ \\
\hline Personal cases & $\mathbf{3 1 2}$ & $\mathbf{2 6 7 - ( 8 5 , 5 8 \% )}$ \\
\hline
\end{tabular}

(23) found the location of myocardial bridges at the anterior interventricular artery in $96.52 \%$ of cases, (27) in $95 \%$, (35) in $84.71 \%$, and $(19,20)$ in $70 \%$ of cases. (36) states that myocardial bridges are met at the anterior interventricular artery, and $(25,26)$ states that the higher frequency of myocardial bridges in this artery is not in relation to age, sex or ethnicity. The most common differences in the location of myocardial bridges occurred in the anterior interventricular artery, where the percentages 
ranged between $34.5-100 \%$ of the cases, $(28,30)$ found only at the level of this artery. Our results are lower by $0.13-14.42 \%$ of cases compared to the results found at $(9,23,27,28,31,33,34)$ and higher by $0.87-51.08 \%$ of cases in relation to (4, $14,19,20,24,26,29,32,33,35)$. The unique myocardial bridges at IVA level were found in 195 cases, $62.50 \%$ of all bridges and $68,99 \%$ of the left coronary artery myocardial bridges, and double bridges we met in 36 cases ( 72 myocardial bridges), $23,06 \%$ of all bridges and $26,97 \%$ of the left coronary artery myocardial bridges. (9) finds a single case $(0.18 \%$ of cases) with 3 myocardial bridges located at the anterior interventricular artery, a variant tha we have also encountered in one case.

Table 2 The location of the single myocardial bridges in the anterior interventricular artery

\begin{tabular}{|l|c|c|c|}
\hline Author & Upper third & Middle third & $\begin{array}{c}\text { Lower } \\
\text { third }\end{array}$ \\
\hline Irvin & - & $59.12 \%$ & $6.29 \%$ \\
\hline Cay & - & $52.79 \%$ & $47.21 \%$ \\
\hline Kantarci & $9.09 \%$ & $68.18 \%$ & $22.73 \%$ \\
\hline Konen & - & $57.45 \%$ & $14.89 \%$ \\
\hline Johansen & - & $69 \%$ & - \\
\hline Carrascosa & - & $90.38 \%$ & $9.62 \%$ \\
\hline Jin Ho Hwang & $0.36 \%$ & $96.18 \%$ & $3.45 \%$ \\
\hline Wirianta & $13.2 \%$ & $77.6 \%$ & $9.2 \%$ \\
\hline Donkol & - & $24.6 \%$ & $3.7 \%$ \\
\hline En-Sen Ma & - & $60.41 \%$ & - \\
\hline Yu-Jun Niu & - & $74.29 \%$ & $11.63 \%$ \\
\hline Muzafer & $6.1 \%$ & $47.5 \%$ & $9.8 \%$ \\
\hline Personal cases & $\mathbf{3 3 . 3 3 \%}$ & $\mathbf{6 6 . 6 7 \%}$ & - \\
\hline
\end{tabular}

The location of the anterior interventricular artery myocardial bridges was found at the upper third level of this artery more frequently by $21.86-34.68 \%$ versus $(9,30,38,39)$, this localization not being reported by $(4,23)$. The largest variations we encountered in the location of myocardial bridges at the middle third of the anterior interventricular artery, our results being lower by $2.47-41.20 \%$ versus $(4,9,24,28,30$, $33,37,38)$, but higher by $2.19-30.38 \%$ than the results of $(5,23,39)$.

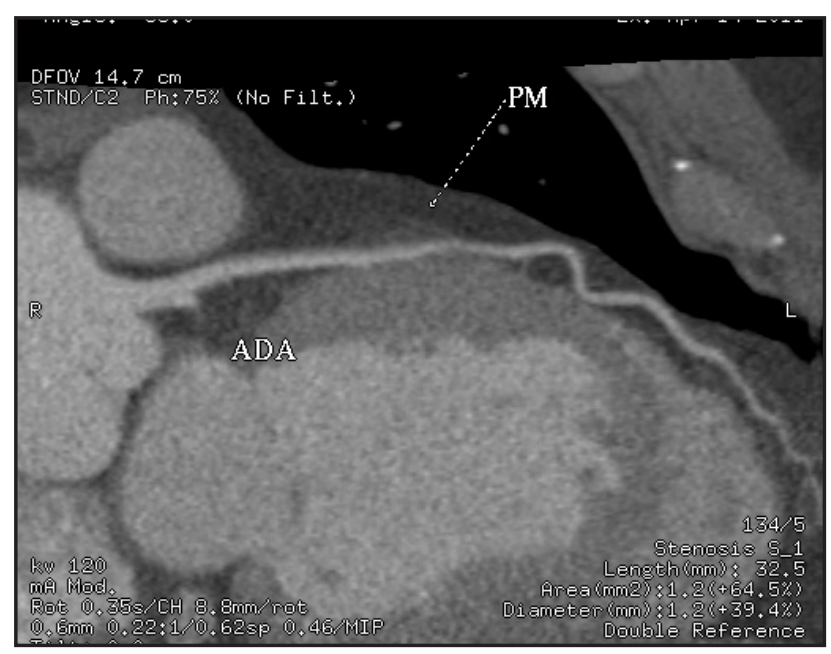

Figure 1 Myocardial bridge located in the upper third of the anterior interventricular artery male gender, $1.8 \mathrm{~mm}$ thick, $32.5 \mathrm{~mm}$ long; tunneling artery diameter of $1.2 \mathrm{~mm}$ $(+39.4 \%)$ and $1.2 \mathrm{~mm}^{2}$ area (+64.5\%).

We did not encounter myocardial bridges located in the lower third of the anterior interventricular artery, aspect reported in a percentage of $3.45-47.21 \%$ by $(5,9,23,24,28$, $31,38,33,39,44)$. After (27) myocardial bridges are located at the middle and distal third of the anterior interventricular artery in $95 \%$ of cases and after (35) they are located at the same levels as (27) in $84.71 \%$ of cases. (40) finds them most frequently in the middle of the anterior interventricular artery, $(19,20)$ quoting Wissler, states that they are most commonly located at 2-3 $\mathrm{cm}$ from the origin of anterior interventricular artery, (41) placing them most frequently at $2 \mathrm{~cm}$ of the left coronary artery ostium.

Table 3 The thickness of the myocardial bridges

\begin{tabular}{|l|c|c|}
\hline Author & Thickness $(\mathrm{mm})$ & $\begin{array}{c}\text { Average } \\
\text { thickness(mm) }\end{array}$ \\
\hline Kantarci & $1.2-3.3$ & 2.5 \\
\hline Guang & $1-35$ & - \\
\hline Jacobs & - & 2.6 \\
\hline Jin Ho Hwang & - & $3+/-1.4$ \\
\hline Jodocy & - & $2.6+/-1.6$ \\
\hline Li Jian-Ju & $1-4$ & - \\
\hline Donkol & $1-6.2$ & $2.3+/-3.9$ \\
\hline En-Sen Ma & $1.6-5$ & $2.7+/-0.7$ \\
\hline Yu Jun Niu & - & $2.15+/-0.74$ \\
\hline Muzafer E & $0.5-7$ & - \\
\hline Personal cases & $\begin{array}{c}\mathbf{0 . 7 - 5 . 7} \\
\text { Male: } \mathbf{1 . 7 - 5 . 7} \\
\text { Female: } \mathbf{0 . 7}-\mathbf{5 . 2}\end{array}$ & $\mathbf{3 . 0 1}$ \\
\hline
\end{tabular}




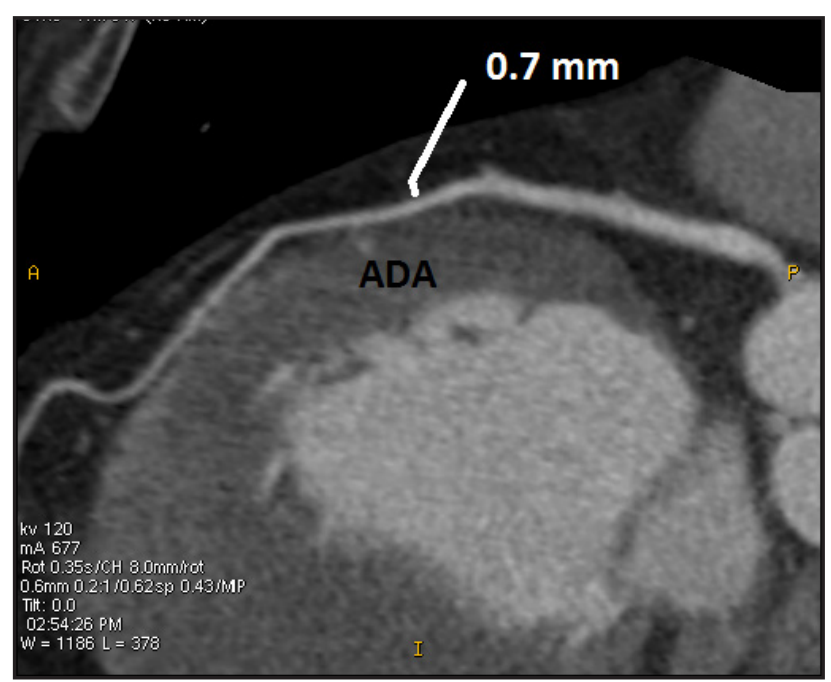

Figure 2 Myocardial bridge located in the middle third of the anterior interventricular artery in the female gender, $0.7 \mathrm{~mm}$ thick.

In terms of thickness of myocardial bridges, we found it higher in male gender than female gender, with the difference being $0.5 \mathrm{~mm}$ in the case of the maximum thickness and $1 \mathrm{~mm}$ in the case of the minimum thickness. The minimum thickness found by us is smaller by $0.3-0.9$ $\mathrm{mm}$ from $(4,12,24,26,30)$ and $0.2 \mathrm{~mm}$ larger than the minimum thickness found by (28). The maximum thickness we found is smaller by 0.5 $1.3 \mathrm{~mm}$ compared to $(5,39)$ and higher by $0.7-2.4$ $\mathrm{mm}$ from the maximum thickness found by (16, $30,33,42)$. By comparing the average thickness of the myocardial bridge found by us with the literature data, we have always found it higher by $0.01-0.86 \mathrm{~mm}$ versus $(9,30,32,33,40)$. The largest thickness of the myocardial bridge was found at the anterior interventricular artery, followed by the thickness at the right coronary artery, at the circumflex and left marginal arteries, the myocardial bridges having a close thickness, but smaller than the first two arteries. Thickness of myocardial bridges is different in systolic and diastolic, with the systole being thicker by $0.1-1$ $\mathrm{mm}$.

Myocardial bridges may be complete and incomplete and, after their thickness, have been classified into superficial and deep. After (9) myocardial bridges are superficial when they have a thickness equal to or greater than $1 \mathrm{~mm}$ and after (32) when they have a thickness greater than $2 \mathrm{~mm}$. (9) finds superficial myocardial bridges in $66,07 \%$ of cases, of which $65,22 \%$ of cases are complete, the deeper myocardial bridges found in $33,93 \%$ of the cases. (34) find the superficial myocardial bridges in $65.43 \%$ of the cases, the deep ones being in $34.57 \%$ of the cases. (43) found the incomplete superficial myocardial bridges in $40.91 \%$ of cases, the complete superficial ones in $18.69 \%$ of the cases, the deep ones finding them in $40.40 \%$ of the cases. (32) finds at the anterior interventricular artery level that deep myocardial bridges are more common (58.82\% of cases) than superficial (41.18\%). We found that the superficial myocardial bridges (with a thickness less than $2 \mathrm{~mm}$ ) are in a percentage of $42.31 \%$ of cases, the deep ones being more common (57.69\% of cases). We found great differences in the two genders, in male gender the superficial myocardial bridges were in a percentage of $28.57 \%$ of cases, while in female the superficial myocardial bridges we found it in $42.31 \%$ of the cases, the deep myocardial bridges being more common in male with $29.76 \%$ of female. Compared to the results from the literature, the superficial myocardial bridges we found it in a lower percentage by $2.29-23.76 \%$ compared to $(9,32,34,43)$, towards these authors finding deep myocardial bidges more frequent with $19,93-27.18 \%$. In the case of double myocardial bridges, we found at the level of the anterior interventricular artery that the lower bridge had a lower thickness with 0.4-1.6 mm.

Table 4 The length of myocardial bridges.

\begin{tabular}{|c|c|c|}
\hline Author & Lenght (mm) & Average lenght $(\mathrm{mm})$ \\
\hline Kantarci & $6-12$ & 17 \\
\hline Konen & $13-40$ & - \\
\hline Sirus & - & $19.6+/-4.9$ \\
\hline Guang & - & $2.32+/-0.95$ \\
\hline Liu H & $5-120$ & 30.5 \\
\hline $\begin{array}{l}\text { Qian Ju- } \\
\text { Ying }\end{array}$ & - & $20.9+/-7.5$ \\
\hline L1 Jian-Ju & $4-40$ & - \\
\hline Donkol & $6-24$ & $15+/-7$ \\
\hline En-sen Ma & $8-40$ & $17.6+/-5.7$ \\
\hline Yu-Jun Niu & - & $21.8+/-5.98$ \\
\hline Jodocy & - & $14.8+/-6.5$ \\
\hline Muzafer & $5-40$ & - \\
\hline $\begin{array}{l}\text { Personal } \\
\text { cases }\end{array}$ & $\begin{array}{c}\text { 9.4-73.1 } \\
\text { Male: } 9.4-73.1 \\
\text { Female: } 11.9-28.7\end{array}$ & $\begin{array}{l}26.51 \\
28.95 \\
20.66\end{array}$ \\
\hline
\end{tabular}


For (40) the myocardial bridge length is $23.4 \mathrm{~mm}$ and for (14) $31 \mathrm{~mm}$. (17) finds that the myocardial bridge length is up to $10 \mathrm{~mm}$ in $5.26 \%$ of cases, in $42 \%$ of cases the myocardial bridge length was $10-20 \mathrm{~mm}$, and in $26.32 \%$ of myocardial bridges the length was over $20 \mathrm{~mm}$. For (27) the myocardial bridge length is up to $10 \mathrm{~mm}$ in $58 \%$ of cases, in $32 \%$ of cases the myocardial bridge length is between $10-20 \mathrm{~mm}$ and in $10 \%$ of cases the myocardial bridges had a length of over $20 \mathrm{~mm}$.

We found described in the literature that the length of myocardial bridges as being between 4-120 mm, and we found it between 9.4-73.1 $\mathrm{mm}$. The minimum length in the literature (4$13 \mathrm{~mm}$ ) is less than that we found by $1-5 \mathrm{~mm}$ $(5,16,24,30,31,33,39)$. The maximum length of myocardial bridges in the literature is 12-120 $\mathrm{mm}$, being less than that we found by 31.1-61.1 $\mathrm{mm}$ at $(16,24,30,33,39)$ and greater by $46,9 \mathrm{~mm}$ from (31). The average length of the myocardial bridges, which we found $26.51 \mathrm{~mm}$, is higher than in the literature with 4.71-24.19 mm versus $(5,17,30,32,33,42,44)$ and smaller by 3.99 $\mathrm{mm}$ from (31).

The smallest length of myocardial bridge we found it at the anterior interventricular artery, male gender, the female gender having the minimum length higher with $2.5 \mathrm{~mm}$. The largest length was found in the right coronary artery, male gender, and the maximum length of myocardial bridge was smaller with $44.4 \mathrm{~mm}$.

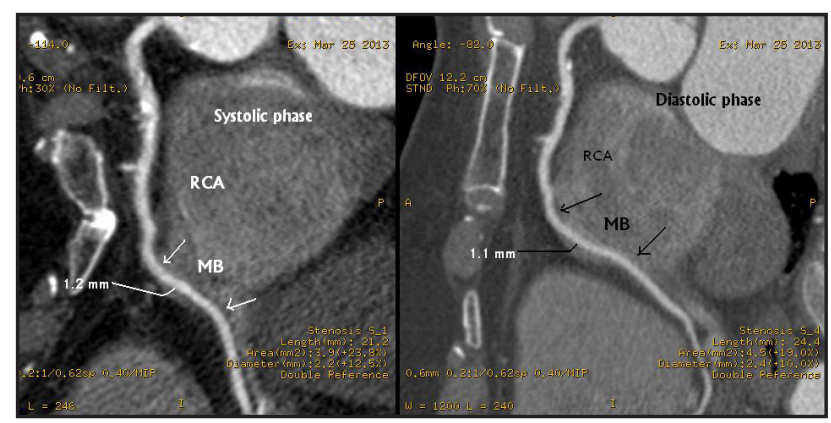

Figure 3 Myocardial bridge located in the upper third of the posterior interventricular artery in female gender. In the systole the thickness of the myocardial bridge is 1.2 $\mathrm{mm}$, the length of $21 \mathrm{~mm}$, the tunneling diameter of 2.2 $\mathrm{mm}(+12.5 \%)$ and the area of $3.9 \mathrm{~mm}^{2}(+33.8 \%)$. In diastole the thickness of the myocardial bridge is $1.1 \mathrm{~mm}$, the length of $24.4 \mathrm{~mm}$, the tunneling diameter of $2.4 \mathrm{~mm}$ $(+10.0 \%)$ and the area of $4.5 \mathrm{~mm}^{2}(+19.0 \%)$.
At the level of the anterior interventricular arteries the length of myocardial bridges was 9.4$34.3 \mathrm{~mm}$, the average being $23.5 \mathrm{~mm}$, the male gender 9.4-34.3 $\mathrm{mm}$ (average $25.08 \mathrm{~mm}$ ), and female gender of 11.9-24.4 mm (average 20.66 $\mathrm{mm}$ ). Thus, between the maximum length of myocardial bridge in the two genders there is a difference of $9.9 \mathrm{~mm}$, the difference between the average length being $4.22 \mathrm{~mm}$, both differences in favor of the male gender. Myocardial bridges had a longer length in diastole than the systole, with a difference of $2-3.4 \mathrm{~mm}$ at the anterior interventricular artery.

Table 5 The tunneling artery caliber in systole

\begin{tabular}{|l|c|}
\hline Author & Caliber $(\mathrm{mm})$ \\
\hline Konen & $1.6+/-0.6$ \\
\hline Donkol & $1.6+/-0.5$ \\
\hline En-sen Ma & $1.1+/-0.4($ average $0.3-2.3)$ \\
\hline Liu H & $1.3-2.8$ (average 2.3$)$ \\
\hline Personal cases & $\begin{array}{c}\mathbf{1 . 2}-\mathbf{2 . 2} \text { (average } \mathbf{1 . 5 8}) \\
\text { Male: } \mathbf{1 . 3}-\mathbf{1 . 9} \text { (average } \mathbf{1 . 6}) \\
\text { Female: } \mathbf{1 . 2}-\mathbf{2 . 2} \text { (average } \mathbf{1 . 5 8})\end{array}$ \\
\hline
\end{tabular}

The largest caliber was found in the anterior interventricular artery in female gender, at the male gender the maximum caliber being $0.3 \mathrm{~mm}$ lower. The minimum caliber we found it the same for both genders, and the average caliber is higher for the male with only $0.02 \mathrm{~mm}$. Compared with the literature, where the average caliber is between 1.1-1.6 mm, in our cases the average caliber is smaller by $0.02-0.78 \mathrm{~mm}$ versus $(5,24,31)$ and higher with $0.48 \mathrm{~mm}$ from (33).

The caliber difference between arterial diameter at myocardial bridge and arterial caliber above the bridge was found to be between 0.4-0.8 $\mathrm{mm}$ in cases with deep myocardial bridges (being lower at the bridge level by $15.79-30 \%$ ), this difference being lower in cases with superficial myocardial bridges (0.1-0.3 $\mathrm{mm})$, sometimes the tunneling artery can keep the caliber above the myocardial bridge. The diameter of the same artery below myocardial bridge is $0.1-0.3$ $\mathrm{mm}$ higher, $6.25-9.52 \%$ higher than myocardial bridge. In the diastole, the caliber returns to normal, but in over $30 \%$ of cases it persists in a reduced decrease. 


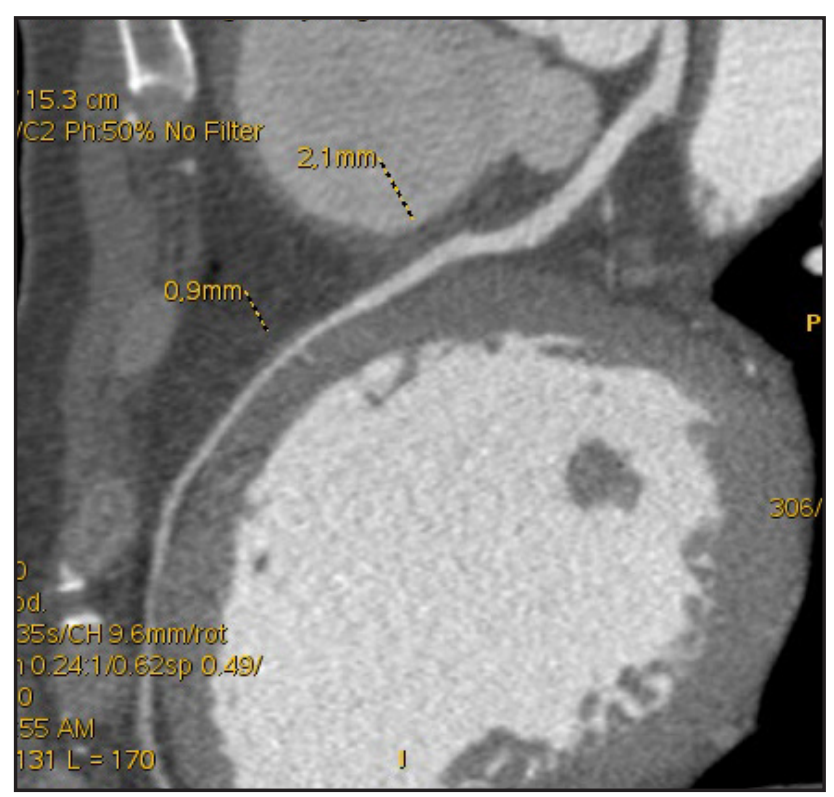

Figure 4 Double myocardial bridges case located on the anterior interventricular artery in male gender: first one(superior) located in the upper third having a thickness of $2.1 \mathrm{~mm}$; the second one (inferior) located in the upper part of the middle third, with a thickness of 0.9 mm.

The diameter of the tunneling anterior interventricular artery was found in the systole between 1.3-2.2, in the male gender the maximum diameter being $0.3 \mathrm{~mm}$ smaller than the female gender. The systolic / diastolic caliber difference of the tunneling artery in the anterior interventricular artery we found it higher in the diastole by $0.1-0.7 \mathrm{~mm}$.

After (3) the diameter of the tunneling artery is reduced by up to $25 \%$ after (6) the artery can be compressed between $15-70 \%$, reaching up to $90 \%$ after (45) and (46) reducing the diameter in the systole of the anterior and posterior interventricular arteries can reach up to $90-100 \%$. (24) finds the caliber reduction at the bridge level by $0.6 \mathrm{~mm}$. (47) finds a sudden stenosis in the systole $(24.36 \%)$, in the diastole being normal. (17) finds the caliber reduction in myocardial bridge by up to $50 \%$ in $47.37 \%$ of cases, up to $70 \%$ in $31.58 \%$ of cases, up to $90 \%$ in $15.79 \%$ of cases and over $90 \%$ in $5.26 \%$ of cases. (26) found that in $70.51 \%$ of the cases there was an insignificant narrowing, only in $5.13 \%$ of the cases there was a significant narrowing in the systole. (21) found that a dynamic compression exists only in $13.33 \%$ of the cases, existent only $(97.5 \%)$ in those with complete myocardial bridge on the anterior interventricular artery, regardless of the presence of the muscles above. After (45) the compression of the tunneling artery exists in $45.3-54.2 \%$ of the cases. (22) found the reduced caliber at the myocardial bridge level comparing to the proximal caliber in $47.37 \%$ of the cases. After (5) in the complete myocardial bridge the arterial diameter was reduced in systole to $8.10 \%$ compared to the proximal segment in $54.66 \%$ of cases, and in diastole the arterial lumen was decreased by $0.38 \mathrm{~mm}$ in $12.75 \%$ of the cases. (5) finds at the myocardial bridge level on the anterior interventricular artery reduction of the diameter by up to $1.2 \mathrm{~mm}$ from the proximal caliber in $42.86 \%$ of the cases.

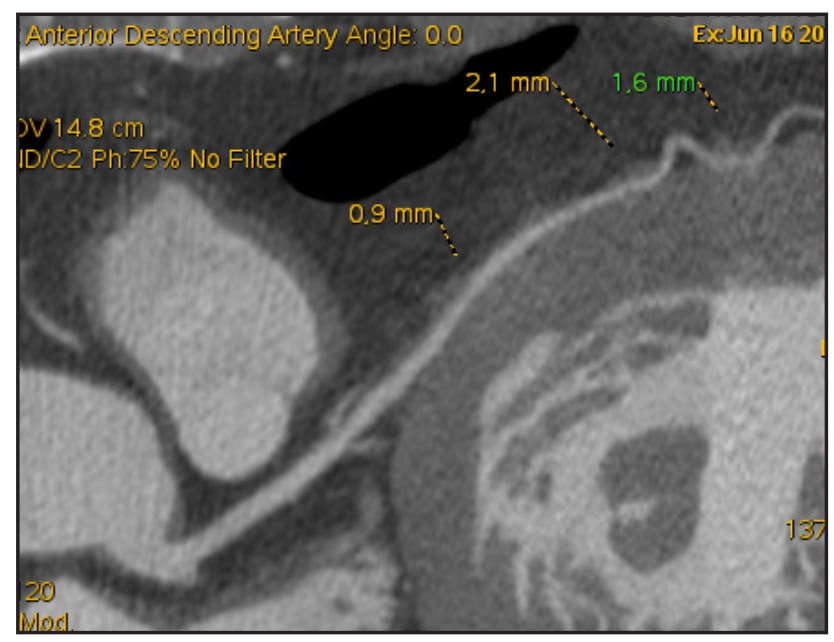

Figure 5 Case with 3 myocardial bridges: superior, in the upper part of the middle third, thickness: $0.9 \mathrm{~mm}$; middle, in the lower part of the middle third, thickness: $2.1 \mathrm{~mm}$; inferior, in the lower third of the anterior intervertebral artery, thickness: $1.6 \mathrm{~mm}$.

The area was found to be between 1.2$3.9 \mathrm{~mm}^{2}$, the minimum limit being the same for both genders, the maximum limit being higher for females by only $0.1 \mathrm{~mm}^{2}$. At the anterior interventricular artery area, the area ranged between the same limits for both sexes (1.2-3.8 $\mathrm{mm}^{2}$ ). Between systole and diastole the area showed a difference in IVA of $0.1-0.4 \mathrm{~mm}^{2}$, in favor of diastole.

\section{Conclusions}

Our study is certainly unique in this area of Romania, treating the characteristics of myocardial bridges at the level of the anterior interventricular artery almost under 
all morphological aspects. At the same time, a comparison of myocardial bifurcation characteristics with the results described by authors from all parts of the globe is made, as can be seen in the article and the bibliography.

Our results were obtained by coronary angiographic CT exams performed in people who addressed the physician for cardiac symptomatology, but also to those who addressed the specialist for a routine exam. The myocardial bridges are congenital disorders that raise important clinical problems through their complications, which frequently go to sudden death, the severity of a myocardial bridge being given by the length and especially the thickness of it, which are responsible for the degree of compression of the tunneling artery.

We have not encountered cases of myocardial bridges that might interest the anterior interventricular arterial branch over its entire length or at its terminal branch.

Taking into account the frequency of complications in people with myocardial bridges (see sudden deaths on sports grounds or at work), it is necessary to control coronary vasculature through angioCT, especially in performance athletes or those who make great efforts to exercise the profession, even when the person does not show any symptoms, making an active identification of the population. Last but not least, the importance of the presence of myocardial bridges for cardiac transplantation should be emphasized.

The statistical differences in literature are explained by the number of cases that the study performed, the performance of the device that has been worked and the attention and experience of the staff working in the respective medical service. We do not exclude predisposition to the frequency of myocardial bridges depending on the geographical area or even on ethnicity.

We also recommend the use of names in the existing international anatomical nomenclature

\section{References}

1. Möhlenkamp S, Hort W, Ge J, Erbel R. Update on myocardial bridging. Circulation. 2002 Nov 12;106(20):2616-22.
2. Ceausu M, Ionescu RA, Malinescu B, Rusu MC, Hostiuc S, Dermengiu D. Sudden cardiac death due to triple myocardial bridging associated with atypical coronary topography. Rom J Morphol Embryol. 2013 Jan 1;54(3 Suppl):833-7.

3. Theron HDu T, Kleynhans PHT, MARX JD, JORDAAN PJ. Myocardial bridging as a cause of myocardial infarction - A case report. South African Medical Journal. 1988 Sep 1;74(5):243-4.

4. Carrascosa P, López EM, Capunay C, Deviggiano A, Vallejos J, Carrascosa J. Prevalence and characteristics of myocardial bridges in multidetector row computed tomography coronary angiography. Rev Argent Cardiol. 2009;77:268-73.

5. Donkol RH, Saad Z. Myocardial bridging analysis by coronary computed tomographic angiography in a Saudi population World J Cardiol, 2013; 5(11):434-441

6. Stables RH, Knight CJ, McNeill JG, Sigwart $\mathrm{U}$. Coronary stenting in the management of myocardial ischaemia caused by muscle bridging. Heart, 1995; 74(1):90-92

7. Dermengiu D, Vovolis I, Hostiuc S, Curcă GC, Rusu MC, Luca L. Morphological features in myocardial bridging. Rom J Leg Med, 2010; 18(3):163-170

8. Lu GM, Zhang LJ, Guo H, Huang W, Merges RD. Comparison of myocardial bridging by dual-source $\mathrm{CT}$ with conventional coronary angiography. Circulation Journal. 2008;72(7):1079-85.

9. Hwang JH, Ko SM, Roh HG, Song MG, Shin JK, Chee HK, Kim JS. Myocardial bridging of the left anterior descending coronary artery: depiction rate and morphologic features by dual-source CT coronary angiography. Korean journal of radiology. 2010 Oct 1;11(5):514-21.

10. Wan L, Wu Q. Myocardial bridge, surgery or stenting?. Interactive cardiovascular and thoracic surgery. 2005 Dec 1;4(6):517-20.

11. Basso C, Thiene G, Mackey-Bojack S, Frigo AC, Corrado D, Maron BJ. Myocardial bridging, a frequent component of the hypertrophic cardiomyopathy phenotype, lacks systematic association with sudden cardiac death. European heart journal. 2009 
Apr 30;30(13):1627-34.

12. Kosiński A, Grzybiak M. Myocardial bridges in the human heart: morphological aspects. Folia Morphologica. 2001;60(1):65-8.

13. Poláček P. Relation of myocardial bridges and loops on the coronary arteries to coronary occlusions. American heart journal. 1961 Jan 1;61(1):44-52.

14. Loukas M, Curry B, Bowers M, Louis Jr RG, Bartczak A, Kiedrowski M, Kamionek M, Fudalej M, Wagner T. The relationship of myocardial bridges to coronary artery dominance in the adult human heart. Journal of anatomy. 2006 Jul;209(1):43-50.

15. Arya D, Chauhan K, Bansal M, Mehta CD. Morphological study on myocardial bridges and its clinical significance. Journal of surgery. 2013;2(1):32-7.

16. Li JJ. Is myocardial bridging a bridge connecting to cardiovascular events? Chinese medical journal. 2010 Apr 1;123(7):964-8.

17. Darabian S, Amirzadegan A, Sadeghian H, Sadeghian S, Dehkordi MR, Goodarzynejad H. Clinical and Angiographic Characteristics of Myocardial Bridges: a Descriptive Report of 19 Cases and Follow-up Outcomes. The Journal of Tehran University Heart Center. 2007;2(2):105-10.

18. Singh H, Singh C, Kumar A, Aggarwal N, Banerji A. Acute myocardial infarction secondary to myocardial bridge treated with drug-eluting stent. Indian Heart Journal. 2005;57(6):734-7.

19. Ishii T, Asuwa N, Masuda S, Ishikawa Y, Kiguchi H, Shimada K. Atherosclerosis suppression in the left anterior descending coronary artery by the presence of a myocardial bridge: an ultrastructural study. Modern pathology: an official journal of the United States and Canadian Academy of Pathology, Inc. 1991 Jul;4(4):424-31.

20. Ishii T, Asuwa N, Masuda S, Ishikawa Y. The effects of a myocardial bridge on coronary atherosclerosis and ischaemia. The Journal of Pathology: A Journal of the Pathological Society of Great Britain and Ireland. 1998 May;185(1):4-9.

21. Kim PJ, Hur G, Kim SY, Namgung J, Hong SW, Kim YH, Lee WR. Frequency of myocardial bridges and dynamic compression of epicardial coronary arteries: a comparison between computed tomography and invasive coronary angiography. Circulation. 2009 Mar 17;119(10):1408-16.

22. Baptista CA, DiDio LJ. The relationship between the directions of myocardial bridges and of the branches of the coronary arteries in the human heart. Surgical and Radiologic Anatomy. 1992 Jun 1;14(2):137-40.

23. Nalinakumari, Vinay K, Sasi K, Gugapriya. Morpho - Histological Study Of Myocardial Bridges Of Cadaveric Hearts. Journal of Evidence Based Medicine and Healthcare. 2015;2(7):851-8.

24. Konen E, Goitein O, Sternik L, Eshet Y, Shemesh J, Di Segni E. The prevalence and anatomical patterns of intramuscular coronary arteries: a coronary computed tomography angiographic study. Journal of the American College of Cardiology. 2007 Feb 6;49(5):587-93.

25. Bourassa MG, Butnaru A, Lespérance J, Tardif JC. Symptomatic myocardial bridges: overview of ischemic mechanisms and current diagnostic and treatment strategies. Journal of the American College of Cardiology. 2003 Feb 5;41(3):351-9.

26. Zeina AR, Odeh M, Blinder J, Rosenschein U, Barmeir E. Myocardial bridge: evaluation on MDCT. American Journal of Roentgenology. 2007 Apr;188(4):1069-73.

27. La Grutta L, Runza G, Lo Re G, Galia M, Alaimo V, Grassedonio E, et al. Prevalence of myocardial bridging and correlation with coronary atherosclerosis studied with 64-slice CT coronary angiography. Radiol Med. 2009;114(7):1024-36

28. Irvin RG. The angiographic prevalence of myocardial bridging in man. Chest. 1982 Feb 1;81(2):198-202.

29. Juillière Y, Berder V, Suty-Selton C, Buffet $\mathrm{P}$, Danchin N, Cherrie F. Isolated myocardial bridges with angiographic milking of the left anterior descending coronary artery: a long-term follow-up study. American heart journal. 1995 Apr 1;129(4):663-5.

30. Kantarci M, Duran C, Durur I, Alper F, Onbas O, Gulbaran M, Okur A. Detection of myocardial bridging with ECG-gated MDCT 
and multiplanar reconstruction. American Journal of Roentgenology. 2006 Jun;186(6 supplement_2):S391-4.

31. Liu $\mathrm{H}$, Huang MP, Liang $\mathrm{CH}$, Zheng JH, $\mathrm{Wu} \mathrm{ZB}$. Detection and its clinical value of myocardial bridging with 64-slice spiral CT coronary angiography. Nan fang yi ke da xue $x u e$ bao $=$ Journal of Southern Medical University. 2009 Feb;29(2):236-8.

32. Jodocy D, Aglan I, Friedrich G, Mallouhi A, Pachinger O, Jaschke W, Feuchtner GM. Left anterior descending coronary artery myocardial bridging by multislice computed tomography: correlation with clinical findings. European journal of radiology. 2010 Jan 1;73(1):89-95.

33. Niu YJ, Zhang XL, Cao AD, Leng B. Clinical value of the correlations of mural coronary artery compression extent with myocardial bridge length and thickness evaluated by 128-slice CT. Experimental and therapeutic medicine. 2013 Mar 1;5(3):848-52.

34. Sildiroglu O, Cuce F, Isilak Z, Saglam M, Incedayi M, Kara K, Ozturk E. Does Myocardial Bridging Affect Coronary Hemodynamics\&63. Archives of Clinical and Experimental Surgery. 2013 Jan 1;2(4):219-23.

35. Rubinshtein R, Gaspar T, Lewis BS, Prasad A, Peled N, Halon DA. Long-term prognosis and outcome in patients with a chest pain syndrome and myocardial bridging: a 64-slice coronary computed tomography angiography study. European Heart Journal-Cardiovascular Imaging. 2013 Jan 29;14(6):579-85.

36. Brodsky SV, Roh L, Ashar K, Braun A, Ramaswamy G. Myocardial bridging of coronary arteries: A risk factor for myocardial fibrosis?. International journal of cardiology. 2008 Mar 14;124(3):391-2.

37. Johansen C, Kirsch J, Araoz P, Williamson E. Detection of myocardial bridging by 64row computed tomography angiography of the coronaries. Journal of computer assisted tomography. 2008 May 1;32(3):448-51.

38. Wirianta J, Mouden M, Ottervanger JP, Timmer JR, Juwana YB, de Boer MJ, Suryapranata H. Prevalence and predictors of bridging of coronary arteries in a large
Indonesian population, as detected by 64-slice computed tomography scan. Netherlands Heart Journal. 2012 Oct 1;20(10):396-401.

39. ELMALI M, GÜLEL O, ASLAN S, SOYLU K, ÇELENK Ç. Prevalence and Imaging Findings of Myocardial Bridging on Multi-Slice CT Coronary Angiography. Turkiye Klinikleri Cardiovascular Sciences. 2009;21(2):211-5.

40. Jacobs JE, Bod J, Kim DC, Hecht EM, Srichai MB. Myocardial bridging: evaluation using single-and dual-source multidetector cardiac computed tomographic angiography. Journal of computer assisted tomography. 2008 Mar 1;32(2):242-6.

41. Ishikawa Y, Akasaka Y, Suzuki K, Fujiwara M, Ogawa T, Yamazaki K, Niino H, Tanaka M, Ogata K, Morinaga S, Ebihara Y.Anatomic properties of myocardial bridge predisposing to myocardial infarction. Circulation. 2009 Aug 4;120(5):376-83.

42. Lu GM, Zhang LJ, Guo H, Huang W, Merges RD. Comparison of myocardial bridging by dual-source $\mathrm{CT}$ with conventional coronary angiography. Circulation Journal. 2008;72(7):1079-85.

43. Kim SS, Ko SM, Song MG, Hwang HG. Systolic luminal narrowing and morphologic characteristics of myocardial bridging of the mid-left anterior descending coronary artery by dual-source computed tomography. The international journal of cardiovascular imaging. 2011 Dec 1;27(1):73-83.

44. Qian JY, Zhang F, Min D, Lei GE, Liu $\mathrm{XB}$, Bing FA, Wang QB, Cui SJ, GE JB. Prevalence and characteristics of myocardial bridging in coronary angiogram-data from consecutive 5525 patients. Chinese medical journal. 2009 Mar 1;122(6):632-5.

45. McCrindle BW, Yetman AT. Myocardial bridging of the left anterior descending coronary artery in children with hypertrophic cardiomyopathy. Journal of the American College of Cardiology. 2001 Sep 1;38(3):9212.

46. HU XY, Zhou DX, Qian JY, Zhang F, Pan CZ, GE JB. Multiple myocardial bridges affecting left anterior descending artery and right coronary artery with hypertrophic cardiomyopathy: a case report. Chinese 
medical journal. 2007 Apr 1;120(8):734-6.

47. Chiung-Zuan Chiu, Jun-Jack Cheng, ShenChang Lin, Shih-Huang Lee,Peiliang Kuan, Kuo-Gi, Shyu, Ming-Tsung Chen, YenKung Chen, Alfred C Liao, Yeh-You Shen. Computed Tomography in Patients with Myocardial Bridge. Ann Nucl Med Sci. 2004; 18:9-16 